\title{
A clínica em movimento na saúde de TTTS: caminho para materialização do SUS entre travestis, transsexuais e transgêneros
}

\author{
Clinics on the move in TTT's health: the path to materialization of SUS among transvestites, \\ transsexuals and transgendered
}

Eduardo Corsino Freire', Fátima Cristina Alves de Araujo², Ândrea Cardoso de Souza³, Dalvani Marques $^{4}$

\footnotetext{
${ }^{1}$ Mestre em Ciências pela Fundação Oswaldo Cruz (Fiocruz) - Rio de Janeiro (RJ), Brasil.

edcorsino@oi.com.br

${ }^{2}$ Mestre em Saúde Coletiva pela Universidade do Estado do Rio de Janeiro (UERJ) - Rio de Janeiro (RJ) Brasil. Professora do Instituto Federal de Educação, Ciência e Tecnologia do Rio de Janeiro (IFRJ) - Rio de Janeiro (RJ), Brasil. fatimacaa@hotmail.com

${ }^{3}$ Doutora em Saúde Pública pela Escola Nacional de Saúde Pública Sérgio Arouca, da Fundação Oswaldo Cruz (ENSP/Fiocruz) - Rio de Janeiro (RJ), Brasil. Professora do Departamento de Enfermagem Materno Infantil e Psiquiátrica, da Escola de Enfermagem da Universidade Federal Fluminense (UFF) Niterói (RJ), Brasil.

andriacz@ig.com.br

${ }^{4}$ Doutora em Enfermagem pela Universidade de São Paulo (USP) - São Paulo (SP) Brasil. Professora da Faculdade de Enfermagem da Universidade Estadual de Campinas (Unicamp) - Campinas (SP), Brasil.

marquesdal@yahoo.com.br
}

RESUMO: O movimento de lésbicas, gays, bissexuais, travestis, transexuais e transgêneros (LGBTTT) tem estimulado a visibilidade da temática da homossexualidade e da multiplicidade de expressões e identidades de gênero no Brasil. Apesar de haver avanços, como a formalização de programas governamentais e o incremento do debate público, persistem desafios. A problemática da saúde no universo TTT é abordada ressaltando o limitado direito à saúde e ao acesso a ações e serviços de saúde, o preconceito e a discriminação sofridos pela inadequação dos profissionais e dos recursos tecnológicos utilizados. Finaliza-se com a indicação da clínica peripatética, para contribuir para a efetivação do direito à saúde.

PALAVRAS CHAVE: Transexualidade; Identidade de gênero; Políticas públicas.

ABSTRACT The movement of lesbian, gay, bisexual, transvestites, transsexuals and transgendered (LGBTTT) increased visibility of the topic of homosexuality and the multiplicity of expressions and gender identities in Brazil. Despite having advances, as the formalization of government programs and the increase of public debate, the challenges remain. The problematic of health in the TTT universe is approached, emphasizing the limited right to health and access to health actions and services, prejudice and discrimination suffered by the inadequacy of professional and technological resources used. Thus, it emphasizes the peripatetic clinic to contribute to the realization of the right to health.

KEYWORDS: Transsexuality; Gender identity; Public policies. 


\section{Universo TTT}

Observa-se, nos últimos anos, um crescimento do movimento de lésbicas, gays, bissexuais, travestis e transexuais (LGBT), da visibilidade das questóes que envolvem a temática da homossexualidade e da multiplicidade de expressóes e identidades de gênero no Brasil. Se há avanços, especialmente no que se refere a travestis, transexuais e transgêneros, representados, principalmente, pela formalização de programas governamentais e pelo incremento do debate público, há também desafios (FACCHINI, 2009), estando um eles no setor saúde.

Apesar de serem escassos os estudos que abordam essa população no Sistema Único de Saúde (SUS), há evidências de que fatores relacionados à organização dos serviços, à postura de profissionais, ao estigma e ao constrangimento vivenciado pela população trans comprometem a materialização dos princípios e diretrizes do SUS junto ao grupo.

\section{Mas que universo Trans é esse?}

O movimento que abarca homossexuais e o universo trans ${ }^{1}$ é, hoje, um sujeito político bastante complexo, formado por múltiplas categorias identitárias, nem sempre movidas pelos mesmos discursos. Sem a consideração dessa problemática, torna-se difícil compreender muitas das posiçóes referentes ao mercado segmentado ou mesmo a relação com outros atores sociais que integram o seu campo de ação (FRANÇA, 2006).

Facchini (2005) propóe uma periodização do movimento homossexual, considerando uma 'primeira onda', demarcada pelo surgimento do Grupo Somos e do jornal O Lampião da Esquina (1978), e uma 'segunda onda', associada ao surgimento dos grupos Triângulo Rosa (Rio de Janeiro), Grupo Gay da Bahia (Salvador) e, também, do Atobá (Rio de Janeiro), nos anos 1980. O autor identifica uma 'crise' nos primeiros anos da epidemia de Aids e um 'reflorescimento' do ativismo nos anos

\footnotetext{
1 Universo trans refere-se ao grupo formado por travestis, transexuais e transgêneros,
}

1990 (FACCHINI, 2005). Algumas das características desse novo período são a diversificação e a especificaçáo crescentes das categorias identitárias abarcadas pelo movimento - em um modelo que, inspirado na experiência internacional, especialmente a norte-americana, é definido por Facchini como 'segregacionista'.

Efetivamente, os nomes dos encontros nacionais de entidades homossexuais, ocorridos ao longo dos anos 1980 e 1990, expressam a diversidade de siglas, multiplicadas para acomodar as diferentes expressóes identitárias produzidas através de um processo contínuo de segmentação (RAMOS; CARRARA, 2006). Assim, se os seis primeiros encontros (1980-1992) foram chamados de Encontros Brasileiros 'de Homossexuais'; o sétimo (1993) chamou-se Encontro Brasileiro de 'Lésbicas e Homossexuais'; o oitavo, Encontro Brasileiro de 'Gays e Lésbicas'; o nono (1997) intitulou-se Encontro Brasileiro de 'Gays, Lésbicas e Travestis'. Após isso, e até o XII Encontro, realizado nas dependências do Congresso Nacional, em 2005, os encontros foram designados como Encontros Brasileiros de 'Gays, Lésbicas e Transgêneros' (RAMOS; CARRARA, 2006).

Esse crescente e contínuo movimento pelo reconhecimento da relação entre o direito - entendido como ordenamento jurídico, isto é, o conjunto de instrumentos normativos estatais vigente num determinado momento em um determinado país, englobando atos legislativos e decisóes judiciais - e a sexualidade não é novidade. Tradicionalmente, o direito estatal foi produzido como instrumento de reforço e de conservação dos padróes morais sexuais majoritários e dominantes. Vale dizer que esse direito atua na confirmação de determinadas relaçóes e práticas sexuais hegemônicas. Exemplo disso é a consagração da família nuclear pequeno-burguesa, a atribuição de direitos e deveres sexuais entre os cônjuges e a criminalização de atos homossexuais (RIOS, 2011).

A emergência de movimentos sociais, reivindicando a aceitação de práticas e relações divorciadas desse modelo, levou à arena política e, consequentemente, ao debate jurídico a questão dos direitos sexuais, especialmente dos direitos LGBT. O surgimento dessas demandas e o reconhecimento de alguns direitos, ainda que de modo lento e não uniforme, inauguraram uma nova 
modalidade na relação entre os ordenamentos jurídicos e a sexualidade. Historicamente, concentrando-se na modernidade, percebe-se o irromper desses direitos a partir dos anos 1980, tomando por marco o julgamento, pela Corte Europeia de Direitos Humanos, do primeiro caso em que uma lei criminalizadora da sodomia foi afastada por violar um direito humano básico, qual seja, a privacidade (RIOS, 2011).

No Brasil, o conjunto das Conferências Estaduais LGBT, realizadas entre março e maio de 2008, contou com cerca de 10 mil participantes, e resultou num total consolidado de 510 propostas, avaliadas e complementadas na etapa nacional. A Conferência Nacional LGBT, de 2008, contou com a presença do presidente da República, de ministros e representantes do movimento, que discursaram, causando grande impacto na mídia e no movimento. O Brasil foi o primeiro país a promover uma atividade dessa natureza, o que sinaliza o compromisso do Estado brasileiro com a promoção dos direitos de LGBT (BRASIL, 2008; FACCHINI, 2009).

Numa retrospectiva acerca de gênero e políticas públicas, é possível delinear um processo no qual a redemocratização do Estado brasileiro - que envolveu a democratização de processos decisórios e a inclusão de novos segmentos populacionais como beneficiários de políticas públicas - coincide com o fortalecimento dos movimentos de mulheres e feministas. Processos igualmente complexos, envolvendo uma gama diversa de atores políticos, em âmbito nacional e internacional, desenvolveram-se com relação a outros sujeitos políticos ou segmentos populacionais, a partir dos anos 1990. Assim, observam-se na agenda política brasileira as primeiras referências ao que seriam as 'açôes afirmativas', com foco na redução das desigualdades de gênero, no combate ao racismo e nas políticas envolvendo outros recortes populacionais, como é o caso de jovens, idosos e LGBT. A partir de meados dos anos 1990, é possível acompanhar todo um processo de multiplicação de sujeitos políticos no campo dos movimentos sociais e de "focalização da focalização" nas políticas públicas (FACCHINI, 2009).

Atualmente, pressuposta a homossexualidade como tema político, os movimentos agregam lésbicas, gays, bissexuais, travestis, transexuais e transgêneros. A expansão dos coletivos vai se configurando no denominado Movimento LGBTTT, cujas reflexôes e práticas ativistas têm promovido na sociedade brasileira mudanças de valores. Mudanças essas que geraram visibilidade, no campo político, para os problemas que envolvem essas pessoas.

O pluralismo de siglas para designar as diversas identidades das categorias ativistas engloba grupos de indivíduos movidos pelos mesmos discursos, mas que se reconhecem como diferentes. Essas diferenças, que muitas vezes não são bem entendidas pela sociedade, nos fazem refletir sobre quem são realmente esses indivíduos e o que os diferencia. Se a sociedade entende como lésbicas as mulheres que se relacionam sexualmente com outras mulheres, como gays os homens que mantêm relações sexuais com outros homens e como bissexuais os indivíduos que mantêm relaçóes sexuais com homens e mulheres, onde se encaixariam os grupos de TTTs?

Ora, travestis não se enquadram bem nos discursos das ciências sociais e humanas, em geral, entre o construtivismo e o essencialismo, justamente por serem, ao mesmo tempo, os dois. Esse grupo entende que homens são homens e mulheres são mulheres em função das suas genitálias, sendo essa uma dimensão essencialista. Por outro lado, a morfologia diferencial da genitália permite desvendar diferentes possibilidades de gênero. Em síntese, Kulick (2008) as define como essencialistas construtivas.

No entanto, travestis não são mulheres. Poderiam, então, ser definidas como homens? Para Kulick (2008), isso não é claro, de imediato. A subjetividade de travestis torna-se viável devido à crença em conexôes entre o corpo e sua atividade sexual. Isso posto, sua subjetividade é resultado da configuração de sexo (biológico), gênero e sexualidade, especificada na sociedade em que vive. No Brasil, não é costumeiro encontrar na literatura referências a um terceiro gênero (ternarismo). Os autores que assim postulam estão seguindo linhas norte-americanas, que argumentam em favor da ambiguidade e da diversidade de travestis. De fato, travestis não se reconhecem como homens e nem como mulheres (KULICK, 2008).

A concepção de gênero no Brasil parece estar mais relacionada com a função da genitália do que, simplesmente, com as diferenças anatômicas. O critério 
determinante na identificação de homens e mulheres parece estar mais relacionado com o papel que a genitália desempenha no intercurso sexual. O ponto fundamental aqui é a penetração, sendo homem o indivíduo que só penetra. Se a pessoa é penetrada, é diferente de homem, podendo ser uma mulher ou não. Assim, a relevância entre homem e mulher não é tão significativa, mas, sim, a entre quem apenas realiza penetração em uma relação sexual e aqueles que são penetrados. Temos, então, um sistema binarista entre homens e não homens (KULICK, 2008).

O contrastivo 'não homem' possibilita a emergência de travestis, e todos aqueles indivíduos (do sexo masculino ou feminino), cujo desejo é ser penetrado, pertencem à mesma categoria classificatória, compartilhando o mesmo lado do binarismo de gênero. Esse fato pode explicar por que as travestis não se identificam como mulheres nem manifestam desejo de realizar cirurgias de mudança de sexo, ainda que pretendam se tornar mais femininas. Do ponto de vista cultural, como travestis já se enquadram no mesmo gênero em que as mulheres, a transgenitalização não lhes traria nada do que já não possuam. Sendo assim, a cirurgia significaria retirar uma fonte de prazer e renda (KULICK, 2008).

$\mathrm{O}$ fato de travestis não realizarem cirurgias de mudança de sexo e compartilharem do mesmo gênero que mulheres suscita algumas questôes: a quem interessa a cirurgia? Ou mesmo, quem são os indivíduos transexuais?

A nomenclatura transexualismo é utilizada para definir as pessoas que vivem uma contradição entre o corpo e a subjetividade. Na perspectiva lógica da patologização, são transexuais femininos aqueles que passaram por processo transsexualizador de mulher para homem, e transexuais masculinos os que passaram de homem para mulher. Tal abordagem nega e recorda a todo tempo que esses indivíduos nunca serão homens ou mulheres de verdade, pois o gênero que significará o transexual será o de nascimento.

Tendo-se como referenciais suas subjetividades frente à pluralidade e às construçóes de sentidos para os conflitos com o corpo, o que faz um sujeito se afirmar como pertencente a um determinado gênero é o sentimento. Sendo assim, a nomenclatura mais bem empregada é a que considera como sendo mulheres transgêneros aqueles indivíduos que se sentem como mulheres, e homens transgêneros os que se sentem homens. Uma vez que a transformação do corpo por meio de hormônios já é suficiente para lhes garantir um sentido de identidade, eles não reivindicam cirurgias de transgenitalização para garantir um sentido identitário (BENTO, 2006).

$\mathrm{Na}$ cultura brasileira, são observados diferentes grupos que realizam diversas transformaçóes de gênero. A noção de transexual parece de difícil adequação por ser criada a partir de saberes das ciências médicas e psicológicas, dotados de pressupostos universalizantes e homogeneizantes. No entanto, é possível traçar características marcantes desse grupo. Benedetti (2005), em seu estudo envolvendo mulheres transexuais, sinaliza que elas dominam uma linguagem médico-psicológica refinada, explicam e demonstram seu modo de ser apoiando-se nos saberes dessas disciplinas, que muitas vezes já estão desacreditados. Reconhecem-se doentes, e a cirurgia apresenta-se como correção ou ajustamento de seu corpo à sua personalidade. As transexuais não aceitam suas genitálias e negam terem nascido homens.

Tradicionalmente, os estudos sobre transexuais são realizados pelas ciências da área 'psi', tendo-se certa ausência da sociologia, o que conota um sentido de conflitos individuais e, de certa forma, reforça a patologizaçáo da identidade, construídos fora do referencial biológico. Contudo, esses estudos habilitam aqueles designados como pervertidos, desviados, psicóticos, enfermos e transtornados, incluindo-se as transexuais, travestis, lésbicas, bissexuais e gays como sujeitos que constituem suas identidades de gênero mediante os mesmos processos que os considerados "normais" (BENTO, 2006).

Os estudos sobre gênero, inicialmente, vieram para tentar dar uma explicação à subordinação da mulher. Com a afirmativa de que "mulher não nasce, torna-se", Simone de Beauvoir, em 1949, dá consistência ao 'tornar-se', construindo um movimento de desnaturalização (mas não de dessencialização) da identidade feminina. Dois gêneros e subjetividades diferentes, uma concepção binária que reproduz o pensamento moderno para os sujeitos universais, onde cada um ocupa um lugar fixo dentro dessa estrutura binária hierarquizada. Porém, em se tratando da transexualidade, nada é objetivo, e, nesse caso, os efeitos de um regime regulador, que toma os 
gêneros com base na natureza, orientam o olhar classificador e normatizador de especialistas sobre aqueles que reivindicam o direito ao reconhecimento da mudança de gênero em sua totalidade, incluindo cirurgias de correção da genitália (BENTO, 2006).

Pensando-se o gênero como uma criação da sociedade, com significação das diferenças dos corpos sexualizados, firma-se uma dicotomia entre sexo (natureza) e gênero (cultura). Seguindo esse pensamento, cada cultura moldaria suas marcas nesse corpo inerte, sexualmente diferenciado pela natureza. Há uma amarração no sentido de que o corpo remete ao sexo e que o gênero só pode ser entendido quando correlacionado com tal pensamento. Assim, o corpo nasce maculado pela cultura, no entanto, o processo de transexualização é marcado por conflitos, que trazem à tona ideologias de gênero, colocando transexuais em transaçóes constantes com as normas de gênero (BENTO, 2006).

Travestis, transexuais e transgêneros, em constantes transações de sua identidade e seus gêneros, estão em um processo de incorporação perene. Ao mimetizarem mulheres ou homens e ao interferirem no próprio corpo, esses sujeitos podem ser pensados como incorporados. A incorporação estaria vinculada à mimesis, onde o corpo é um meio de expressão. Os TTTs estão, constantemente, preocupados com a reconstrução do corpo, e, com isso, (re)constroem seus gêneros, identidades e pessoas. Entretanto, esses sujeitos querem dar a maior 'naturalidade' possível aos seus gestos. Enfim, por meio da 'montagem', produzem e reproduzem femininos/ masculinos, revelando a multiplicidade do gênero, porém, também explicitando - por uma (re)orientação da duplicidade - que as ideias de gênero e sexo podem ser conturbadas. Ou seja, se a duplicidade é vivida como constituinte do reconhecimento do sexo (homem ou mulher), travestis, transexuais e transgêneros mostram que a questão é mais complexa (JAYME, 2001).

\section{E como fica o acesso à saúde no universo TTT?}

Ao abordar a problemática da saúde no universo TTT, o primeiro ponto a ser destacado relaciona-se ao direito à saúde, que é conceituado como categoria de direito subjetivo público, a partir do reconhecimento do sujeito como detentor do direito e do Estado como obrigado a garanti-lo, sem, é claro, eximir a responsabilidade do próprio sujeito, que também deve cuidar de sua saúde. Esse direito, no Brasil, está genericamente consagrado pela Constituição Federal de 1988, que, além de considerar o direito à saúde em seu sentido mais amplo (reconhecendo seus determinantes e condicionantes - alimentação, moradia, saneamento, meio ambiente, renda, trabalho, educação, transporte etc.), cria, ainda, o Sistema Único de Saúde (BRASIL, 1990). Sob tal perspectiva, cabe ao Estado a promoção da saúde, através de políticas sociais e econômicas, visando à redução do risco de doenças, bem como do acesso, de forma universal e igualitária, a açóes e serviços de promoção, proteção e recuperação (BRASIL, 1988). Dessa forma, a saúde não pode ser vista isoladamente das condiçôes que envolvem o indivíduo e a coletividade (SANTOS, 2010).

Contudo, o texto legal somente direciona as ações de saúde, as quais são produzidas a partir do trabalho vivo, em ato no cotidiano dos serviços. Segundo Cecílio (2001), a garantia da materialização do direito à saúde, incluindo o acesso universal e equânime de todos os cidadãos, representa um desafio para o setor saúde, pautado, essencialmente, na micropolítica do trabalho cotidiano. O Ministério da Saúde, tentando defender os direitos de indivíduos e coletivos com relação à saúde, elaborou a Carta dos Direitos dos Usuários, contemplando os diversos grupos sociais e possibilitando uma discussão qualificada (BRASIL, 2010). Visando a reorientar as políticas de saúde e objetivando a ampliação do acesso a ações e serviços de qualidade, essas políticas têm reafirmado o compromisso do SUS com a integralidade e a universalidade, por contamplarem ações voltadas para a promoção, prevenção e recuperação da saúde (BRASIL, 2010).

O reconhecimento dos direitos de TTT, com preocupaçôes na área da saúde pública, corrobora as demandas relacionadas aos direitos sociais (RIOS, 2011). Promovendo os direitos fundamentais dessa população, como a inviolabilizaçáo do direito à vida, à igualdade e à liberdade, dispostos no art. $5^{\circ}$ da constituição Federal, tenta-se combater o estigma e a discriminação 
por orientação sexual e identidade de gênero (BRASIL, 2010). A discriminação por identidade de gênero incide na determinação social da saúde nos processos de sofrimento e adoecimento decorrentes do preconceito e do estigma social (BRASIL, 2010).

TTTs enfrentam discriminação e estigmatização, muitas vezes na infância, quando começam a aparecer como diferentes, gerando, como resultado mais direto, o analfabetismo e/ou a não finalizaçáo de seus estudos (WOLFE, 2011). Todas as dificuldades advindas do preconceito, enfrentadas por esses indivíduos na sociedade, também são refletidas nos serviços de saúde. Percebe-se que alguns grupos sociais ainda continuam a receber um tratamento diferenciado, como se fossem cidadãos com menos direitos do que os demais (MÜLLER; KNAUTH, 2008).

A garantia do direito à saúde para a população TTT, na perspectiva do SUS, passa por um atendimento humanizado e livre de preconceito e discriminação por orientação sexual e identidade de gênero, incluindo, como estratégia, o uso do nome social como forma de promoção de acesso ao sistema. Ressalta-se que a entrada nos serviços, como na estratégia de Saúde da Família, demanda conscientização das diferentes modalidades de constituição de redes familiares, distintas do padrão heterossexual, primando pelo respeito à singularidade dos sujeitos e combatendo todas as formas de normatização que impliquem processos de exclusão e discriminação das pessoas. Isso só é conseguido com o rompimento dos processos discriminatórios institucionalizados (LIONÇO, 2008).

O universo 'trans', no entanto, acaba por, na maior parte das vezes, figurar como conceitos sem definição para muitos indivíduos, e, consequentemente, sem a indicação de encaminhamentos pertinentes à especificação da realidade de vida e saúde da população TTT. Políticas públicas, tal como a política nacional de saúde integral de lésbicas, gays, bissexuais, travestis e transgêneros - LGBT (BRASIL, 2010) -, fazem-se necessárias como estratégias de ação em saúde, diante da especificidade das vivências desses grupos, qualificando ações e provocando, transversalmente, diversas áreas técnicas, objetivando a integralidade e a equidade (LIONÇO, 2008).
$\mathrm{O}$ universo trans encontra-se em situação de vulnerabilidade com relação à garantia de direitos humanos básicos, justificando uma política específica de saúde para o grupo, que respeite suas autonomias. A política nacional de saúde LGBT configura-se como uma política transversal, onde o respeito sem preconceito e sem discriminação é valorizado, como fundamento para promoção, proteção, atenção e cuidado à saúde.

O Ministério da Saúde, através da Atenção Básica, vislumbrando ampliar e garantir o acesso da população trans aos serviços de saúde, através de um atendimento humanizado, tenta respeitar os princípios de integralidade, igualdade e equidade da assistência. $\mathrm{O}$ acolhimento de TTTs nos serviço de Atenção Básica aborda um processo onde estarão enredadas ações humanas passíveis de gerar conflitos.

Com o olhar da bioética, reconhecendo a plena cidadania de todos os seres humanos, mais especificamente, os mais vulneráveis, pode-se pensar na busca da convivência entre usuários TTTs e profissionais da saúde. Os problemas éticos que cercam a Atenção Básica estão relacionados às situaçóes mais corriqueiras do cotidiano. Assim, a bioética cotidiana reforça que esses conflitos e dilemas da vida são importantes e merecem ser discutidos, como, por exemplo, a dificuldade do acesso de travestis, transexuais e transgêneros aos serviços de saúde. Acesso esse entendido como o grau de facilidade com que as pessoas obtêm cuidados de saúde (TRAVASSOS; MARTINS, 2004).

A população TTT apresenta novos significados, nos quais estão incluídas as dimensôes das necessidades de saúde, desde os modos de vida ao acesso às tecnologias, à criação de vínculos afetivos entre usuários e serviços e, também, à necessidade de autonomia (CECÍLIO, 2001). Reporta-se, então, a acessibilidade aos serviços de saúde, não se restringindo apenas ao uso ou não dos mesmos, mas incluindo a adequação dos profissionais e dos recursos tecnológicos utilizados às necessidades de saúde dos usuários, afinal, os problemas de saúde dessa população são complexos e suas demandas numerosas (BRASIL, 2010). O uso de serviços depende de fatores predisponentes, das necessidades de saúde e de fatores contextuais, sendo que o uso eficiente e efetivo é dependente dos fatores individuais e de fatores internos 
dos serviços, que interferem na qualidade do cuidado prestado (TRAVASSOS; MARTINS, 2004).

Seguindo essa visão, a Clínica Peripatética surge como uma possibilidade de avivar o trânsito por esse limiar, que vai do exílio à cidadania. Segundo Lancetti (2007), nos sentidos comum do adjetivo e etimológico da palavra, peripatético significa passear, ir e vir conversando. $\mathrm{O}$ autor remonta à Escola Filosófica Peripatética, fundada por Aristóteles, à terapia peripatética, referenciada por Freud, e à ideia peripatética, de Nietzsche, que afirma que as principais ideias surgem durante a caminhada (LANCETTI, 2007).

Para operacionalizar o peripatetismo no cuidado à saúde, é necessário transitar pelos territórios, transpor limites e transbordar os consultórios, utilizando o espaço dentro-fora como facilitador da comunicação, criando vínculos inéditos em uma relação, até então, estereotipada e não terapêutica. No modelo peripatético de atenção em saúde, as açóes devem ocorrer nos territórios geográfico e existencial dos sujeitos, combinando os diversos componentes da subjetividade. $\mathrm{O}$ ato de fazer esse tipo de clínica visa a romper com coletivos altamente repetitivos, organizados de forma tecnoburocrática, onde os profissionais são regidos pelas dificuldades e se fecham de forma corporativista. O modelo peripatético de se fazer saúde busca eficácia e rompe com práticas segmentarizadas e burocráticas. Esse modelo surge como "espírito de inovação e de virulência afirmativa e força de convencimento para confrontar as tradicionais maneiras burocráticas e simplistas feitas para atender" (LANCETTI, 2007).

Trazendo para os grupos de TTTs a clínica peripatética, podemos contribuir para a efetivação do direito à saúde, em seu sentido amplo, garantindo acesso a ações e serviços marcados por um clima de aprendizado e inovação, onde o fazer é disruptivo para as mentalidades corporativistas e estigmatizantes, àqueles que não se adaptam aos protocolos clínicos tradicionais. $\mathrm{O}$ cuidado peripatético se dá através de práticas ousadas, inovadoras e com potencialidade de transformação verdadeiramente terapêutica (LANCETTI, 2007)

\section{Referências}

BENEDETTI, M. R. Toda Feita: o corpo e o gênero das travestis. Rio de Janeiro: Garamond, 2005.

BENTO, B. A reinvenção do corpo: sexualidade e gênero na experiência transexual. Rio de Janeiro: Garamond, 2006.

BRASIL. Constituição da República Federativa do Brasil: promulgada em 05 de outubro de 1988. Disponível em: <www.senado.gov. br>. Acesso em: 10 set. 2011.

Lei 8080 de 19 de setembro de 1990. Disponível em: <http:// www.saude.inf.br/legisl/lei8080.htm>. Acesso em: 10 set. 2011.

BRASIL. Ministério da Saúde. Política Nacional de Saúde Integral de Lésbicas, Gays, Bissexuais, Travestis e Transexuais. Brasilia: Ministério da Saúde, 2010.

BRASIL. Secretaria Especial dos Direitos Humanos. Plano Nacional de Promoção da Cidadania e Direitos Humanos LGBT lésbicas, gays, bissexuais e transexuais. Brasília: SEDH, 2009.
BRASIL. Secretaria Especial dos Direitos Humanos. Texto Base da Conferência Nacional de Gays, Lésbicas, Bissexuais, Travestis e Transexuais. 2008. Disponível em: <http://portal.mj.gov.br/sedh/co/ glbt/texbaglbt.pdf>. Acesso: 10 set. 2011.

CECILIO, L. C. O. As necessidades de saúde como Conceito Estruturante na Luta Pela Integralidade e Equidade na Atenção em Saúde. In: PINHEIRO,R.; MATTOS, R. A.(Org). Os Sentidos da Integralidade na atenção e no cuidado à saúde. Rio de Janeiro: UERJ, IMS, ABRASCO, 2001. p.113-126.

FRANÇA, I. L. "Cada macaco no seu galho?": poder, identidade e segmentação de mercado no movimento homossexual. Revista Brasileira de Ciências Sociais, São Paulo, v. 21, n. 60, p.104-115, 2006. Disponível em: <http://www.scielo.br/pdf/rbcsoc/v21n60/29763. pdf $>$. Acesso em: 15 set. 2011

FACCHINI, R. Sopa de Letrinhas? Movimento homossexual e produção de identidades coletivas nos anos 90. Rio de Janeiro: Garamond, 2005 
FACCHINI, R. Entre compassos e descompassos: um olhar para o "campo" e para a "arena" do movimento LGBT brasileiro. Bagoas, São Paulo, n. 4, p.131-158, 2009.

JAYME, J.G. Travestis, transfromistas, drag-queens, transsexuais: personagens e máscaras no cotidiano de Belo Horizonte e Lisboa. 2001. Tese (Doutorado em Antropologia) - Departamento de Antropologia, Instituto de Filosofia e Ciências Humanas, Universidade Estadual de Campinas, SP.

KULICK, D. Travesti: prostituição, sexo, gênero e cultura no Brasil. Rio de Janeiro: Editora Fiocruz, 2008.

LANCETTI, A. Clínica Peripatética. São Paulo: Hucitec, 2007

LIONÇO, T. Que direito à saúde para a população GLBT? Considerando direitos humanos, sexuais e reprodutivos em busca da integralidade e da equidade. Saúde \& Sociedade, v. 17, n.2, p. 1121, 2008.

MULLER, M. I.; KNAUTH, D. R. Desigualdades no SUS: o caso do atendimento às travestis é 'babado'!. Cadernos EBAPE. BR, v.6, n. 2, jun. 2008.

RAMOS, S.; CARRARA, S. A constituição da problemática da violência contra homossexuais: a articulação entre ativismo e academia na elaboração de políticas públicas. Physis, Rio de Janeiro, v. 16, n. 2, 2006.
RIOS, R.R. Direitos humanos, direitos sexuais e homossexualidade. Amazônica: Revista de Antropologia, v. 3, n. 2, p. 288-298, 2011.

SANTOS, L. Direito a saúde e sistema único de saúde: conceito e atribuições. O que são ações e serviços de saúde. In: SOUZA, A. E. et al. (Org). Direito a saúde no Brasil. São Paulo: Saberes Editoras, 2010.

TRAVASSOS, C.; MARTINS, M. Uma revisão sobre os conceitos de acesso e utilização de serviços de saúde. Cadernos de Saúde Pública, Rio de Janeiro, v. 20, suppl 2, p. 190-198, 2004.

WOLFE, B. M. Travestis brasileiras. Disponível em: <http://portal. saude.gov.br/portal/arquivos/pdf/lei8080.pdf>. Acesso em: 10 set. 2011.

Recebido para publicação em dezembro de 2013

Versão definitiva em dezembro de 2013

Suporte financeiro: não houve

Conflito de interesse: inexistente 